\title{
Cytohistopathological Diagnosis of Solitary Plasmacytoma of Clavicle: A Rare Site for a Rare Tumor
}

\author{
Nirmalesh Mahata ${ }^{1}$, Indranil Chakrabarti ${ }^{2 *}$, Palash Kumar Mandal ${ }^{3}$ and Bidyut K Goswami ${ }^{2}$ \\ ${ }^{1} M A L$ superspeciality Hospital, India \\ ${ }^{2}$ Department of Pathology, North Bengal Medical College, India \\ ${ }^{3}$ Department of Pathology, College Of Medicine and Sagore Dutta Hospital, India
}

Received: January 08, 2018; Published: January 16, 2018

*Corresponding author: Dr. Indranil Chakrabarti, Associate Professor, Department of Pathology, North Bengal Medical College, Sushrutanagar, Darjeeling, West Bengal, India 734012, Tel: 9433187448; Email: drinch@rediffmail.com

Abstract

Plasmacytoma refers to a malignant tumor composed of abnormal plasma cells which grows within soft tissue or within the axial skeleton. There are three distinct groups of plasmacytoma, of which the solitary plasmacytoma of bone (SPB), accounts for 3-5\% of all plasma cell malignancies. The World Health Organization define solitary plasmacytoma of bone (SPB) as a localized bone tumor consisting of plasma cell identical to those seen in plasma cell myeloma, which appears as a solitary lytic lesion on radiological examination. Here, we report a case of a 50-year old male who presented with swelling of the medial end of clavicle of right side and inability to raise his right hand for the last 3 months. Fine needle aspiration cytology revealed cellular smears composed of sheets of plasma cells with bi-nucleate and multi-nucleated forms. The swelling was operated and subsequent histopathology revealed a solitary plasmacytoma of right clavicle.

The absence of any other osteopenic lesion on radiograph, negative bone scan, absence of marrow involvement by plasma cell or any evidence of anemia, hypercalcemia, hyperuricemia, nephropathy, respiratory and urinary tract infection indicated that there was no systemic myeloma. The patient was treated with surgery and radiotherapy. On subsequent follow up at 15 month, the patient developed multiple myeloma. Thus, here we report a very rare case of solitary plasmacytoma of clavicle diagnosed by cytology and later confirmed by histopathology.

Keywords: Solitary Plasmacytoma; FNAC; Multiple Myeloma

Abbreviations: SPB: Solitary Plasmacytoma of Bone; EMP: Extramedullary Plasmacytoma

\section{Introduction}

Plasmacytoma refers to a malignant tumor composed of abnormal plasma cells which grows within soft tissue or within the axial skeleton. There are three distinct groups of plasmacytoma, solitary plasmacytoma of the bone (SPB), extramedullary plasmacytoma (EMP) and systemic myeloma- of which the solitary plasmacytomas of bone (SPB) account for less than $5 \%$ of patients with plasma cell myeloma [1]. The SPB more commonly involves the axial skeleton eg: vertebra, ribs, skull, pelvis, femur, clavicle and scapula [2]. Klein et al. [3] found that only $0.45 \%$ of more than 1300 primary bone tumours involved the clavicle. The World Health Organization define solitary plasmacytoma of bone (SPB) as a localized bone tumor consisting of plasma cell identical to those seen in plasma cell myeloma, which appears as a solitary lytic lesion on radiological examination [2].

\section{Case Report}

A 50-year old male presented with swelling on the medial end of right clavicle with history of difficulty in elevating right arm for last 3 months (Figure 1). On examination, the swelling was non tender with a smooth surface and well defined margins. It was firm in consistency and measured about $2 \mathrm{~cm}$ in diameter. The overlying skin had normal temperature as compared to surrounding area. There was restriction of movement of arm during abduction along with pain. X-ray showed an osteolytic lesion on medial end of right clavicle (Figure 1). Fine needle aspiration cytology was done from the lesion and the smears showed plenty of small plasmacytoid cells in dispersed fashion. Cells had eccentrically placed nuclei, condensed chromatin and some had prominent nucleoli. There was nucleo-cytoplasmic asynchrony. Binucleated cells were also 
seen (Figure 2). Wide excision biopsy from anterior approach was performed and the resected specimen was sent for histopathological examination.

Grossly, the mass was globular and measured $2 \mathrm{X} 3 \mathrm{~cm}$ with surface irregularity and presence of bony tissue along with. Microscopy revealed sheets and clusters of plasmacytoid cells in sheets having eccentrically placed nuclei, coarse condensed "clock-face" chromatin pattern and abundant cytoplasm. Few cells also have prominent nucleoli (Figure 2). Other tests for systemic myeloma were performed to rule out systemic myeloma. There was absence of any evidence of anemia, hypercalcemia, hyperuricemia or nephropathy. The patient refused subsequent radiotherapy. Serum "M" protein was $4 \mathrm{~g} / \mathrm{L}$ but on follow up of 6 month it was found as $35 \mathrm{~g} / \mathrm{L}$. The bone marrow aspiration was normal initially but at 10 month follow-up, the patient developed systemic myeloma.

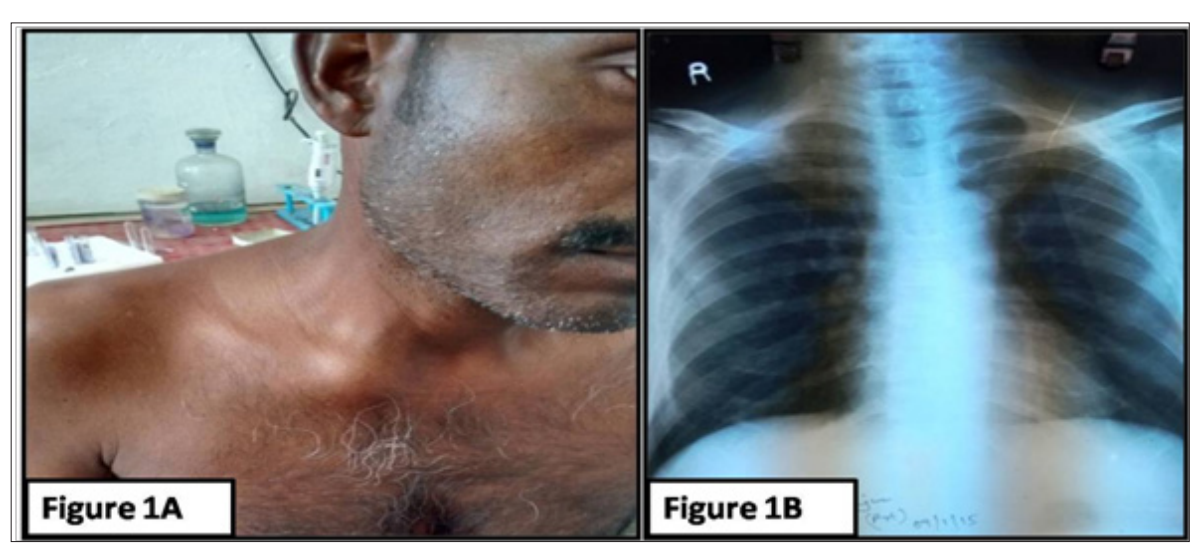

Figure 1: A) Patient having a swelling on the medial end of right clavicle; B) X-ray showing osteolytic lesion on medial end of right clavicle (white arrow).

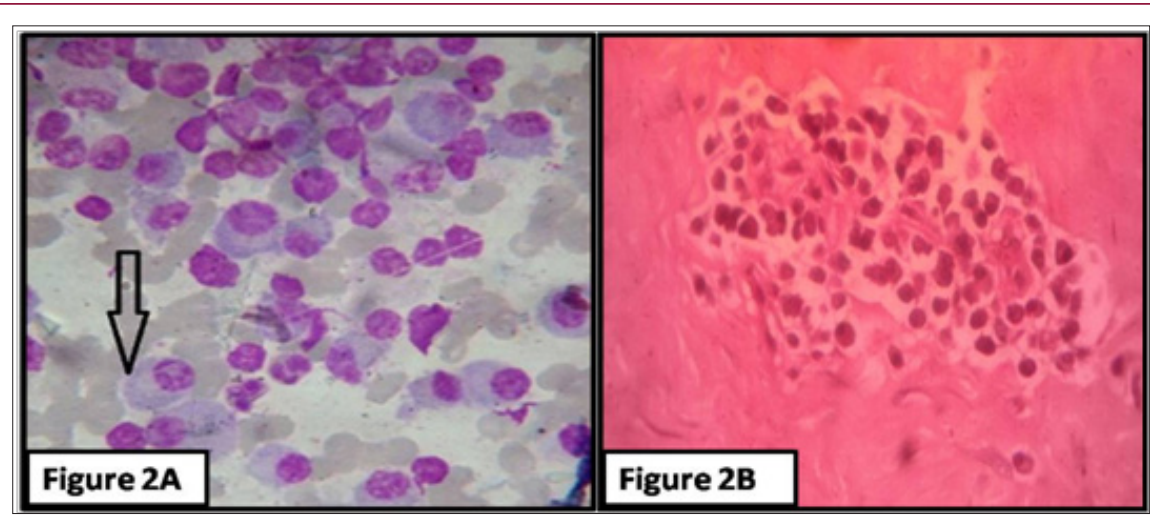

Figure 2: A) Microphotograph showing dispersed population of plasma cells, some plasmablasts showing prominent nucleoli (arrow) (MGG stain; X 400 magnification); B) Microphotograph from histopathological features of clusters and sheets of plasma cells in a fibro-osseous background (H \& E stain; X 400 magnification).

\section{Discussion}

Plasmacytoma can be divided into solitary plasmacytoma of the bone (SPB) and extramedullary plasmacytoma (EMP), both of which are distinct entities. Plasma cell neoplasms account for approximately $1-2 \%$ of human malignancies and occur at a rate of about 3.5/100,000 per year [4,5]. Among these the solitary plasmacytomas of bone (SPB), account for less than $5 \%$ of patients with plasma cell myeloma [1]. The SPB more commonly involves the axial skeleton. Solitary plasmacytoma of the clavicle is rare, and most of the reported SBPs of the clavicle involve the lateral end of clavicle [6-9]. Bone pain is the most common complaint for patients with SPB. The diagnosis is based on histological evidence of a single lesion consisting of monoclonal plasma cells identical to those seen in multiple myeloma along with negative skeletal survey, biochemical assay and no evidence of tumour in the bone marrow.

Association of serum M protein seen among 24-72\% patients of SBP but levels of the M protein tend to be low [10]. The mainstay of treatment is surgical excision. Radiotherapy is helpful for local control and progression of solitary plasmacytoma [11,12]. The patient usually has an excellent disease control with surgery and radiotherapy. Even with treatment, SBPs progress to multiple myeloma in up to $45 \%$ of patients [11-13]. One to 2 years following diagnosis, a persistent serum $\mathrm{M}$ protein level of $5 \mathrm{~g} / \mathrm{L}$ or higher was an additional risk factor for progression [14]. Median time to progression is 2 to 3 years. However, given that multiple myeloma has developed up to 15 years after treatment [12]. In our case, the patient developed multiple myeloma within 10 months of diagnosis of SPB. 


\section{Conclusion}

Thus, we reported a case of solitary plasmacytoma of clavicle which is a rare disease, presenting in an extremely rare site. The diagnosis was confirmed by clinical suspicion, postoperative biopsy, and other investigations relevant to rule out the presence of systemic myeloma. The patient was treated by surgery but could not be treated by subsequent radiotherapy. The patient was followed up for 10 months and there after he presented with multiple myeloma. However, there was no local recurrence.

\section{References}

1. Soutar R, Lucraft H, Jackson G, Reece A, Bird J, et al. (2004) Guidelines on the diagnosis and management of solitary plasmacytoma of bone and solitary extramedullary plasmacytoma. Br J Haematol 124(6): 717-726.

2. Jaffe ES, Harris NL, Stein H, Vardiman JW (1999) World Health Organization Classification of Tumors: Pathology and Genetics, Tumors of Haematopoietic and Lymphoid Tissue. Ann Oncol 213: 490-491.

3. Kleins, Kuppers R (1993) The New England Journal Of Medicine 341: 1520.

4. Bolek TW, Marcus RB, Mendenhall NP (1996) Solitary plasmacytoma of bone and soft tissue. Int J Radiat Oncol Biol Phys 36: 329-333.

5. Tsang RW, Gospodarowicz MK, Pintilie M, Bezjak A, Wells W, et al. (2001) Solitary plasmacytoma treated with radiotherapy: impact of tumor size on outcome. Int J Radiat Oncol Biol Phys 50(1): 113-120.
6. Smith J, Yuppa F, Watson RC (1988) Primary tumors and tumor-like lesions of the clavicle. Skeletal Radiol 17(4): 235-246.

7. Carter PM, Rushman RW (1974) Solitary plasmacytoma of the clavicle. Proc R Soc Med 67(11): 1097-1098.

8. Panagopoulos A, Megas P, Kaisidis A, Dimakopoulos P (2006) Radiotherapy resistant solitary bone plasmacytoma of the clavicle. Eur J Trauma 32: 190-193.

9. Shih LY, Dunn P, Leung WM, Chen WJ, Wang PN (1995) Localised plasmacytomas in Taiwan: comparison between extramedullary plasmacytoma and solitary plasmacytoma of bone. Br J Cancer 71(1): 128-133.

10. Soutar R, Lucraft H, Jackson G, Reece A, Bird J, et al. (2004) Guidelines on the diagnosis and management of solitary plasmacytoma of bone and solitary extramedullary plasmacytoma. Clin Oncol (R Coll Radiol) 16(6): 405-413.

11. Reed V, Shah J, Medeiros LJ, Ha CS, Mazloom A, et al. (2011) Solitary plasmacytomas: outcome and prognostic factors after definitive radiation therapy. Cancer 117(19): 4468-4474.

12. Dimopoulos MA, Moulopoulos LA, Maniatis A, Alexanian R (2000) Solitary plasmacytoma of bone and aymptomatic multiple myeloma. Blood 96(6): 2037-2044.

13. Bolek TW, Marcus RB, Mendenhall NP (1996) Solitary plasmacytoma of bone and soft tissue. Int J Radiat Oncol Biol Phys 36: 329-333.

14. Dingli D, Kyle RA, Rajkumar SV, Nowakowski GS, Larson DR, et al. (2006) Immunoglobulin free light chains and solitary plasmacytoma of bone. Blood 108(6): 1979-1983.

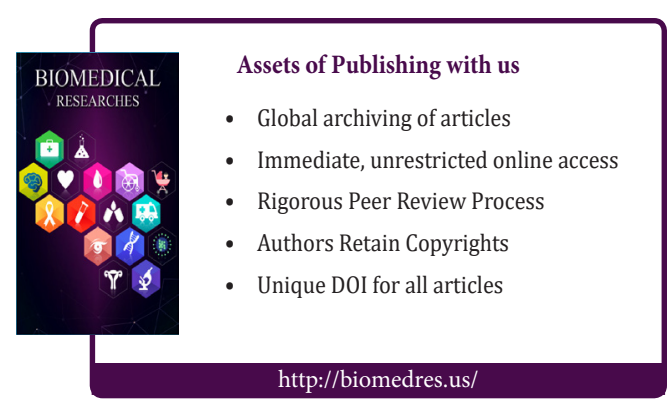

